\title{
HISTORIA DE UNA FASCINACIÓN: BORGES EN HOLANDA
}

\author{
MAARTEN STEENMEIJER \\ Radboud Universiteit Nijmegen, Faculteit der Letteren, Afdeling Romaanse Talen en \\ Culturen, Postbus 9044, 6500 KD, Nijmegen \\ E-mail:m.steenmeijer@let.ru.nl
}

\begin{abstract}
In Out of Context. Historical Reference and the Representation of Reality in Borges, Daniel Balderston claims that the interpretative practice of Jorge Luis Borges's short stories has tended to focus on the 'unreal', that is, on its autoreferential, fictional and fantastic elements, and that, on the other hand, allusions and references to the concrete, historical reality in the work of the Argentinian writer have been disregarded or even neglected. In a departure from this dichotomist perspective, this article proposes a study of Borges's reception in the Netherlands from the very beginning in the fifties until the present day, attempting to ascertain the positions and functions of Borges's work in the Dutch literary system.
\end{abstract}

\section{Introducción}

En Out of Context: Historical Reference and the Representation of Reality in Borges (1993) $)^{1}$ el estudioso norteamericano Daniel Balderston comprueba que la praxis interpretativa de la ficción de Borges ha mostrado una inquietante miopía al centrarse en los elementos autorreferenciales y ficticios o fantásticos en menoscabo de las numerosas referencias a contextos históricos y políticos concretos que ofrecen los cuentos del autor argentino. Balderston refiere sobre todo a la crítica universitaria pero es lícito añadir que sus observaciones valen asimismo para los críticos periodísticos, los autores tributarios a Borges y, muy probablemente, el público lector. Sin negar las excepciones a esta praxis interpretativa ni la presencia de la 'irrealidad' en los cuentos de Borges, Balderston reivindica el estudio de las alusiones y referencias históricas y políticas, alegando que la obra del autor de Ficciones

está íntimamente marcada por el conocimiento de la historia y política argentinas del siglo XX, por la experiencia europea durante y poco después de la Primera guerra 
mundial, por su vinculación con figuras tan apasionadas (y tan radicalmente diferentes entre sí) en sus posturas ideológicas como Leopoldo Lugones, Macedonio Fernández, Victoria Ocampo, María Rosa Oliver y José Bianco. (Balderston 1996, p. 31)

Rastreando estos elementos contextuales comúnmente escamoteados por la crítica en siete cuentos muy conocidos y abundantemente comentados $^{2}$ Balderston relativiza su supuesto carácter abstracto, metafísico, fantástico, autorreferencial, 'irreal'.

La dicotomía establecida por Balderston será el punto de partida de este trabajo. Lo que me propongo es estudiar la presencia de esta visión más bien reductiva de la obra de Borges en Holanda, examinando no sólo sus manifestaciones más importantes sino también las desviaciones de esta tendencia dominante y, además, algunos de los factores que han determinado el estado de las cosas que espero comprobar.

\section{La primera traducción}

Para empezar, cabe destacar que la obra de Borges se introdujo tarde en Holanda. La primera traducción en forma de libro - De Aleph, una antología de cuentos sacados de Ficciones y El Aleph apareció en 1964, es decir doce años después de que se publicó la primera traducción francesa, cinco años después de la primera traducción alemana y dos años después de las primeras traducciones inglesas. ${ }^{3}$ Borges, empero, no era un desconocido en Holanda cuando se publicó De Aleph, lo que, ante todo, se debe precisamente a las primeras traducciones al inglés, alemán y francés, que no quedaron desapercibidas en Holanda. ${ }^{4}$ Así, el primer comentario sobre Borges se escribió con motivo de Fictions y Labyrinthes, las primeras y pioneras traducciones al francés, publicadas en 1952 y 1953, respectivamente. Se trata de un pequeño ensayo de 1954 publicado en la revista literaria Litterair Paspoort, escrito por el autor L.Th. Lehmann. La lectura de los cuentos de Borges le había sido recomendada por nadie menos que Boris Vian. Vale la pena considerar con algún detalle el trabajo de Lehmann, ya que las reservas que él muestra no serían compartidas por críticos posteriores. Es cierto que Lehmann caracteriza a Borges como "un hombre agudo e ingenioso", "Pierre Menard, autor del Quijote" como una obra maestra y Fictions como "un libro afable que despierta la curiosidad" (Lehmann 1954, p. 142) pero también lo es que, según afirma el crítico, Fictions (cuyos textos no serían ni cuentos ni ensayos) pecaría de una falta de sensibilidad: "Parece que los razonamientos abstractos [de Borges] no pueden combinarse con la descripción de acciones 
humanas." ${ }^{5}$ Contextualizando Fictions de una manera singular, Lehmann dice que el libro está contaminado por

esa lánguida sobreintelectualidad que encontramos con gran frecuencia en obras artísticas de los países jóvenes y enérgicos de esos dos continentes al otro lado del Océano, donde desde la llegada de los blancos nunca ha existido un gran artista y donde (tiendo a creer que no se trata de una casualidad) hasta ahora ninguna ciudad ha sido bombardeada completamente a ruinas; una sobreintelectualidad que es relativamente poco frecuente en la literatura de la 'vieja y agotada' Europa. (Ibídem)

El juicio de Lehmann sobre Labyrinthes es más positivo. Sin dejar de destacar los grandes parentescos con Fictions, Lehmann cree que la forma de los textos en el segundo volumen es más concisa y serena, ya que "faltan las largas digresiones eruditas y a veces pedantes" (ibídem) aunque el crítico sigue siendo incapaz de "entregarse" a la obra de Borges ya que ésta trataría más de sistemas que de seres humanos, incluso en el caso del Borges más joven "y acaso más ingenuo" que reconoce en algunas poesías que Lehmann había encontrado en una antología de poesía en lengua española.

En 1958 Lehmann reseña, en la misma revista, la traducción francesa de Otras inquisiciones (Enquêtes 1937-1952, publicada en 1957). Señala los parentescos de los ensayos borgianos con sus ficciones "la fantasía, la perspectiva singular, la lógica insólita, pero también el sentido común" (Lehmann 1958, p. 102) - pero, curiosamente, estas características no le llevan a criticar el libro sino, al contrario, a pasmarse ante su densidad.

En el mismo año aparece en otra revista literaria importante (Maatstaf) el primer cuento de Borges vertido al holandés. Se trata de "Abenjacán el Bojarí, muerto en su laberinto" (El Aleph), traducido y brevemente introducido por el escritor F.C. Terborgh, que había conocido la obra de Borges en Argentina, donde trabajó de diplomático entre 1953 y $1958 .{ }^{6}$

Según he podido averiguar, en los años cincuenta no aparecieron más que estas tres publicaciones sobre Borges. Resulta, pues, que las traducciones francesas y los modestos esfuerzos de dos autores aficionados por despertar interés por el autor argentino no fueron condiciones suficientes para que su obra echara raíces en Holanda. Algunos años después quedaría claro lo que faltaba: traducciones al alemán y al inglés, un premio prestigioso (el del Congreso Internacional de Editores en Formentor, Mallorca, en 1961, compartido con Samuel Beckett) y la subsiguiente publicidad en la prensa extranjera, que fue extensa y eufórica. 
Son factores que se mencionan más de una vez en los comentarios sobre Borges que unos años después empezaron a publicarse en la prensa holandesa. Gracias a su fama internacional, Borges pudo irse convirtiendo en un valor consagrado en los años anteriores a la publicación del primer libro traducido al holandés. No es de extrañar, pues, que más de un crítico reaccionara con cierto alivio cuando apareció De Aleph: "Ahora también hay, por fin, una traducción holandesa." (Nuis 1964) La acogida fue poco menos que abrumadora, según atestiguan las reseñas, todas muy largas y escritas por críticos prestigiosos como J. Bernlef, Kees Fens y Aad Nuis. Así, J. Bernlef ${ }^{7}-$ además de crítico un importante escritor - califica a Borges como "un gran autor" y "un autor moderno de verdad", y sus cuentos como "una revelación". (Bernlef 1964a,b) Para Aad Nuis, éstos son "diversión superior" y tienen "una singular fuerza conmovedora", mientras Borges se le manifiesta como "un autor maravillosamente polifacético al ficcionalizar su cosmovisión". (Nuis 1964) En el prestigioso semanario Vrij Nederland Lehmann - el autor/crítico que introdujo a Borges en Holanda a principios de los años cincuenta - califica argentino como "un erudito increíble", aunque sigue reprochándole su fuerte tendencia a escamotear "obsesiones humanas". (Lehmann 1964) Kees Fens califica a Borges como un autor virtuoso y fuera de lo común (Fens 1964). "Cierto es," dice K. Geenen en de Volkskrant, "que con este Borges ha surgido un autor que tiene mucho que decir al hombre de nuestros tiempos." Y más adelante: "Con el macrocosmos del universo que se expande, Borges quiere ampliar asimismo el microcosmos de la autoconciencia del hombre, y con ello tiene algo profético." (Geenen 1965) La única reserva que tienen los críticos refiere a la traducción, en que, según Kees Fens, figuran bastantes "oraciones feas e incomprensibles" y nombres no traducidos (Fens 1964) mientras que Nuis la caracteriza como "concienzuda pero no tan brillante como Borges hubiera merecido". (Nuis 1964)

Sin dejar de recalcar las cualidades estilísticas y retóricas de los cuentos ("En cada cuento encontramos una redondez rígida y, al mismo tiempo, la sugestión de infinitas posibilidades de interpretación, característica, asimismo, de la mejor poesía", Nuis 1964) los críticos se centran ante todo en el deslumbrante e inquietante talento de Borges de socavar nuestro concepto de la realidad 'mostrando' su carácter ficticio o laberíntico, su vertiginosa mutabilidad, la pasmosa infinidad de posibilidades de interpretarla y los espantosos límites de la capacidad humana para ello. A modo de ejemplo sirva este comentario perspicaz de Kees Fens, el crítico literario holandés más 
importante de la posguerra y, como atestiguan los numerosos artículos que Fens ha dedicado a la obra de Borges en el curso de las últimas décadas, un empedernido aficionado a la misma. Para Borges, escribir es como una creación competitiva:

Los cuentos de Borges suelen ser los cuentos de un sistema - una cosmovisión, una manera de pensar, una argumentación. El hombre se encuentra dentro de este sistema y se convierte en su víctima cuando piense este sistema hasta sus últimas consecuencias. El sistema se adueña, asimismo, del lector por la lógica consecuente e inquebrantable con la que está narrado. La nueva lógica del cuento socava la lógica del lector. Prueba de la fuerza de Borges como autor es que sabe crear un 'contrasistema' convincente y verosímil. [...] El nuevo racionalismo de Borges muestra al lector el absurdo de su propio racionalismo. (Fens 1964)

Este marco abstracto es muy representativo de la acogida de la obra de Borges en Holanda. Si hay una referencia 'real' o concreta en las reseñas, es la mención del país de origen de Borges. Sólo Aad Nuis hace referencia a los cuentos "en que la patria del autor tiene un gran papel, en particular el aguerrido pasado de pampas y gauchos" pero es significativo que añada que se trata de un mundo "muy alejado del resto de su obra". (Nuis 1964)

¿Cómo explicar que todos los críticos hacen caso omiso del contexto histórico y cultural del que proceden y al que refieren muchos cuentos? Ante todo, hay que observar que si el caso holandés es único sólo lo sería de grado, puesto que también en otros países los cuentos de Borges solían ser apreciados e interpretados 'fuera de contexto' (ver, entre otros, Broyles 1981). Los críticos no se sentían 'llamados' a comentar los elementos históricos ('reales'), y ello no sólo por la gran densidad de referencias y alusiones literarias y filosóficas (es decir, 'irreales') sino también porque apenas eran capaces de reconocer aquéllos (me refiero, claro está, ante todo a los elementos americanos propiamente dichos). Los primeros críticos holandeses de Borges no tenían los conocimientos suficientes como para ubicar sus cuentos en su contexto histórico y político. En aquellos tiempos la historia y cultura hispanoamericanas eran todavía terra incognita en Holanda (Steenmeijer 1989, p. 84). Así, en una reseña de Seis problemas para Don Isidro Parodi de Jorge Luis Borges y Adolfo Bioy Casares, el crítico J. van Doorne exclama refiriéndose al país de origen de los dos autores: “¿Qué sabemos de ese gran país en América del Sur? Casi nada. Mucha riqueza y mucha pobreza. Chantaje y corrupción por todas partes." (Doorne 1968) Todavía había que esperar algunos años antes de que se efectuara en 
Holanda el boom del interés por la historia, la cultura y la literatura hispanoamericanas.

En el mismo período, es decir los años setenta, se produjo un boom en la crítica literaria en Holanda. Si en las décadas anteriores los periódicos solían dedicar una sola página por semana a la literatura, ahora publican suplementos semanales de varias páginas. Con ello, fue necesario un reparto del trabajo, y críticos especializados (germanistas, romanistas, anglicistas, hispanistas, etc.) van a compartir la escena con los críticos generalistas que solían llenar las páginas literarias de los periódicos.

Es importante añadir que ya en las décadas anteriores la primera generación de hispanistas holandeses profesionales - J.A. van Praag, C.F.A. van Dam y G.J. Geers - escribió artículos en la prensa holandesa (incluida alguna que otra reseña) para difundir informaciones sobre las letras hispánicas entre el público holandés. No cabe duda, sin embargo, de que su principal campo de interés era la literatura española. Para ellos, la literatura hispanoamericana apenas era más que una asignatura secundaria, una afición. Van Dam y Geers apenas publicaron sobre ella. Van Praag fue más prolífico aunque apenas estaba versado en la nueva narrativa del subcontinente. Es significativo, por ejemplo, que en un artículo panorámico sobre la literatura hispanoamericana publicado en la prestigiosa revista cultural De Gids brillen por su ausencia los autores contemporáneos. La narrativa más reciente que Van Praag comentó fue la novela de la tierra y la poesía más actual la de Gabriela Mistral (Van Praag 1956). El mismo desfase se comprueba en la antología de cuentos hispanoamericanos compilada y traducida por el mismo hispanista S.S. San Juan de Dios. Verhalen uit Latijns-Amerika, aparecida en 1966. Según nos informa el prólogo, la antología contiene "principalmente cuentos de autores contemporáneos". La selección, empero, es casi una anomalía: cuentos de Ventura García Calderón, de Horacio Quiroga, de Rómulo Gallegos y de Rufino Blanco Fombona - para mencionar a los más conocidos - pero ningún cuento 'moderno'. Faltan incluso autores como Carpentier, Borges, Rulfo y Asturias, que ya habían sido lanzados al mercado holandés por aquel entonces. Cierto es que en los años siguientes Van Praag tradujo varios libros de cuentos de Cortázar ${ }^{8}$ pero es importante añadir que no fue por propia iniciativa sino a petición de las editoriales y que, además, los errores en las traducciones dejan traslucir una falta de afinidad con lo fantástico (post)moderno de Cortázar (Steenmeijer 2000). 


\section{Borges en Holanda}

A mediados de octubre del mismo año de publicación de De Aleph1964 - Borges estuvo de visita en Holanda durante cinco días. Fue recibido por el subsecretario de Estado para la educación, el arte y la ciencia, y dio una conferencia sobre la poesía gauchesca en las universidades de Amsterdam y Utrecht. La visita, sin embargo, no fue en primer lugar un acontecimiento oficial ni académico sino literario gracias, ante todo, al histórico encuentro con un grupo de autores holandeses prominentes que tuvo lugar en octubre de 1964 en las oficinas de De Bezige Bij (Amsterdam), hasta el día de hoy la casa editorial holandesa de Borges. Estaban, entre otros, L.Th. Lehmann, Bert Schierbeek, Simon Vinkenoog y Harry Mulisch.

Mulisch es uno de 'los tres grandes' de la narrativa holandesa de la posguerra que en años posteriores tendría fama internacional con novelas como De aanslag (El atentado) y De ontdekking van de hemel (El descubrimiento del cielo). Unos tres años antes del encuentro con Borges, Mulisch había conocido sus cuentos gracias a una traducción alemana que encontró por casualidad en una librería en Amsterdam. Leyó tres oraciones y enseguida cerró el libro. Es curioso cómo, varios años después, el autor holandés recordó este episodio: “i[...] fue como si hubiera leído líneas de mí mismo en otra encarnación!” (Mulisch 1971, p. 55) Además de la proverbial autocomplacencia de Mulisch, se percibe en esta afirmación una mezcla de angustia, asombro y ofensa. Recordando el encuentro con el propio Borges en 1964, Mulisch se expresó en términos más serenos: "Es como uno leyera los sueños que uno acaba de soñar pero ha olvidado." (Bernlef 1964b)

En las décadas posteriores la relación con Borges continuó siendo algo dificultosa. Así, en una entrevista de 1983 Mulisch le reprocha al autor argentino que obedeciera la ley del mínimo esfuerzo por haberse limitado a "inventar" libros en vez de escribirlos. (Meeuse 1983, p. 47) Confiesa, asimismo, que nunca terminó de leer el primer cuento de Borges que conoció - "Tlön, Uqbar, Orbis Tertius" - por miedo de emular a Borges. Pero no vacila en añadir que no le costaría ningún esfuerzo escribir el texto de tres páginas que Borges podría haber escrito a base del mamotreto filosófico del propio $\mathrm{Mu}-$ lisch sobre el origen y el ser del hombre y del mundo, De compositie van de wereld (La composición del mundo, 1980). Esta actitud de superioridad, sin embargo, no deja de inquietarle: "[...] no me siente bien todo lo que acabo de decir. Es como si fuera un traidor. Borges es el único autor al que pedí un autógrafo." (Ibídem: 48) Dada esta actitud ambigua (¿'o se trata más bien de un parricidio fracasado?) sería muy interesante investigar en detalle si la narrativa de Mulisch 
en efecto no ha sido 'contaminada' por la de Borges, un tema que todavía queda por explorar.

Sin tender al parricidio, también Cees Nooteboom - amigo de Mulisch, profundo conocedor del mundo y dela cultura hispánicos y el autor holandés contemporáneo con más fama internacional - se mostró algo incómodo cuando le preguntaron sobre su relación con Borges. Conoció sus cuentos a mediados de los años cincuenta gracias a las traducciones de Roger Caillois. Duda, sin embargo, de que Borges haya marcado su obra. Así, en una entrevista afirma, hablando de su novela corta Een lied van schijn en wezen (Una canción del ser y la apariencia, 1981) que se trata de un libro

muy español. Lo que tú llamas borgiano, yo lo llamo español. El juego del ser y aparecer tiene su origen en el alma española, en Calderón, en La vida es sueño -literatura vertiginosa. De allí lo sacó Borges y de allí lo saqué yo. ${ }^{9}$

En el admirable y conmovedor in memóriam que escribió unos años después, Nooteboom revela el enorme impacto que tuvo la obra de Borges, como atestiguan las dos siguientes citas:

[...] todavía me acuerdo bien de esa sensación de angustia mareante ante la idea de que la realidad, las cosas visibles, existieran exclusivamente por gracia de nuestra percepción, y más cuando Borges en otro ensayo afirmaba que no terminaba ahí, sino que el tiempo tampoco existía. (Nooteboom 1996, pp. 234-235)

Sólo más tarde comprendí que ciertamente todo era serio, pero serio de una manera muy especial, parte de un gran encantamiento literario, y que él utilizaba todos esos elementos y especulaciones en las que se contradecía tan de buena gana para escribir historias y poemas. El no existir, el tener que volver a existir de nuevo, el sosia, el espejo con el otro, o un otro distinto, o nadie en absoluto, todo formaba parte de lo que él llamaba la perplejidad, el constante estado de perplejidad del que está hecha la vida.

El universo de Borges es tal que, si estás inclinado por naturaleza a él, eres absorbido con facilidad durante algún tiempo, y aunque haya períodos de tu vida en los que la necesidad de «realidad» sea mayor que el placer escrupuloso de lo perplejo, sin embargo, siempre volverás a esa obra como alguien con acrofobia vuelve siempre al abismo. (Ibídem: 235)

Afines a las poéticas de Mulisch y de Nooteboom son las ideas desarrolladas por un grupo de novelistas y cuentistas importantes que debutaron en los años setenta, década en que se fundó la importante revista literaria De Revisor. Fue el punto de encuentro de autores como Doeschka Meijsing, Nicolaas Matsier y Frans Kellendonk, que rechazaban la literatura anecdótica del realismo 
epidérmico, transparente y expresivo del yo vigente por aquel entonces y que, aunque sin llegar a la negación ontológica de la realidad de la vertiente más radical del postmodernismo, reivindicaban la imaginación, siendo ésta una facultad para crear

[...] la ilusión de sentido producido por la imaginación debido al que los temas, los motivos, las imágenes y las oraciones son descubrimientos o inventos personales, remedios contra el poder de preguntas atormentadoras, la melancolía, el dolor, la impotencia [...]. (Peeters 1984, p. 9)

Por su elaboración racional de intuiciones se ha denominado a estos autores como

idealistas racionales que consideran sus novelas y cuentos como la respuesta combativa a su alma desconcertada. En su caso la imaginación no es una cuba llena de fantasías sino un instrumento sensible, exacto y preciso, una astucia para hacer frente a la realidad, 'a rainbow across the stormy gloom of the darkest tales' - Nabokov. (Ibídem: 14)

Nabokov, Gombrowicz y Borges fueron los tres grandes maestros de este grupo de jóvenes escritores. El efecto del primer encuentro con la obra de Borges - mucho más fácil y evidente en su caso gracias a las traducciones holandesas disponibles en sus años de formación fue igual de abrumador que en el caso de Mulisch y Nooteboom. Así, cuando en 1967 en una librería Doeschka Meijsing - que acabó de cumplir veinte años y era una estudiante frustrada con ambiciones indefinidas de ser escritora - empezó a leer el lema de Shakespeare en De Aleph - "O God, I could be bounded in a nutshell and count myself a King of infinite space. Hamlet, II, 2" - pensó:

¡Eureka! [...] Me pueden encerrar en los cuartos más oscuros, me pueden aburrir, desesperar [...] pero lo que nunca dejará de ser es que puedo pensar lo que quiera, traer a la mente lo que quiera; nadie puede quitarme el placer que tengo en mi capacidad de imaginar, en cualquier tiempo. (Meijsing 1988, p. 9)

Aunque en la misma conferencia Meijsing también refiere a la temática gauchesca y el fervoroso antiperonismo de Borges, el marco de su exposición - representativo del de sus colegas escritores - es abstracto o, si se quiere, filosófico: la obsesión por el tiempo. Lo que aprendió de Borges fue que era posible "escapar de la presión del tiempo". "El modelo de escape tiene un nombre sencillo: la Biblioteca" (ibídem: 12), dice la autora, quien en otra ocasión ha caracterizado su cuento "Temporis acti" (en De hanen en andere verhalen, 1974) como "un pequeño homenaje a Borges" (Diepstraten y Kuypers 
1978, p. 173) y que ha afirmado que el aleph es un tema recurrente en su obra (ibídem: 174-175).

Fue el Borges 'irreal' el que tuvo un gran impacto en la literatura holandesa, como se puede desprender, asimismo, de la siguiente afirmación de Barber van de Pol. Refiriendo a Harry Mulisch, Kees Fens, Cees Nooteboom, Nicolaas Matsier, Doeschka Meijsing, Frans Kellendonk y Willem Jan Otten, la prestigiosa traductora, crítica y autora dice:

Inventar y razonar con sentido común pero cruzando las armas a gusto con todo el universo mental, incluyendo los mitos, la teología y las reglas del arte: eso es lo que han hecho todos ellos con un valor borgiano, con un valor alimentado por Borges. (Pol 1997, p. 165)

Para la rúbrica "Vertaallaboratorium" (Laboratorio de traducción) del primer número de la revista literaria New Found Land, Van de Pol invitó a cinco otros autores, críticos y/o traductores a comentar el poema "El Angel" (de La cifra) partiendo de la siguiente pregunta: ¿es un creyente el Borges que habla en este poema? La propia Van de Pol y el autor Nicolaas Matsier contestan con un rotundo no. Para ellos "El Angel" es "un acta de no-creencia" (Borges 1981, p. 39) y "una oración paradójica a un Dios en que Borges no cree, una súplica para no caer en súplicas." (Ibídem: 41) La respuesta del crítico Kees Fens es afín a la de Van de Pol y Matsier: "Afirmando a Dios se pide una refutación de Dios." (Ibídem: 44) Según la autora Doeschka Meijsing se trataría más bien de la incierta 'creencia' de Borges en la eternidad, por la cual el autor argentinio entendería que "todo ocurre en un mismo 'momento', [...] que las cosas no tienen duración ni fin." (Ibídem: 43) El traductor y crítico Lemm apenas opina, centrándose más bien en el estoicismo de Borges (ibídem: 47). El comentario que más sorprende es el de Cees Nooteboom, que no vacila en afirmar que "dentro del texto de este poema habla alguien que cree." (Ibídem: 50)

\section{4. ¿Sudamericano?}

Meijsing pronunció su conferencia sobre Borges veinte años después de haber conocido la obra del autor argentino. En el curso de estas dos décadas se había traducido gran parte de la obra de éste. Aparte de los principales libros de cuentos se publicaron varios libros de ensayos, de poesía y uno de conferencias. ${ }^{10}$ Con ello, no se produjejon cambios espectaculares en la recepción, cuyo marco siguió siendo el de la temática de la 'irrealidad', como diría Balderston, con menoscabo de los aspectos históricos y políticos, es decir 'reales'. 
En vistas de este marco de referencia de la recepción, es casi una anomalía el titular de un anuncio que De Bezige Bij publicó en 1977 en algunos periódicos para promocionar la obra de Borges y que reza así: "Sudamericano". Se trata de un intento más bien forzado de 'inscribir' a Borges en el boom de literatura latinoamericana que en Holanda empezó, de hecho, a partir de 1972, año de publicación de la traducción holandesa de Cien años de soledad. Pues el caso es que, a pesar de que se aumentaran el interés y los conocimientos con respecto a la historia, la cultura y la literatura de Latinoamérica, Borges siguió siendo "un gran autor europeo", como dice el título de una reseña de Cees Zoon, el licenciado en Hispánicas que fue a trabajar de corresponsal para uno de los periódicos holandeses de mayor importancia, prestigio y difusión, de Volkskrant, en el cual también colaboró como crítico literario durante algunos años. En su reseña de la versión holandesa de El libro de arena, Zoon sostiene que si por una parte la elite literaria europea endiosa a Borges, por otra "el argentino medio" no pierde el sueño por "la problemática que determina su obra" y muchos de sus compatriotas lo aborrecen por sus ideas políticas reaccionarias y fachosas. Por añadidura, Zoon no vacila en sostener que Borges

siempre se esforzó por defender su posición privilegiada hasta el extremo. Es harto conocido cómo se suele hacerlo en América Latina. Quizás los aficionados europeos de Borges no estén bien informados sobre su andadura política. En el curso de los años siempre ha defendido los numerosos regímenes militares de Argentina. Incluso ahora, a la edad de 78 años y siendo ciego, se empeña en adular dictaduras fascistas. (Zoon 1977)

Según el periodista holandés, Borges habría dicho en más de una ocasión que la gran mayoría de sus compatriotas y de los latinoamericanos son unas nulidades culturales. La cultura de elite encarnada por Borges, añade Zoon, se mantiene gracias a los regímenes militares. Resulta casi redundante decir que con este trabajo mal informado y muy tendencioso Zoon reveló su deplorable incapacidad de orientar a los lectores holandeses en el contexto argentino (y latinoamericano) de la obra y la figura de Jorge Luis Borges.

Cees Zoon se encuentra entre los primeros hispanistas que, en el período del boom, se ocuparon de la obra de Borges. Curiosamente, todos ellos han desarrollado sus actividades fuera del ámbito universitario e incluso del pensamiento académico. Los dos más importantes son Barber van de Pol y Robert Lemm, los principales traductores holandeses de Borges y, además, empedernidos exégetas de la obra del argentino en su calidad de críticos literarios y ensayistas. 
Lemm es el único holandés que ha publicado un libro sobre Borges. Se trata del voluminoso estudio De literator als filosoof. De innerlijke biografie van Jorge Luis Borges (El hombre de letras como filósofo. La biografía interior de Jorge Luis Borges, 1991), en que Lemm pasa revista a las fuentes filosóficas (y literarias) de Borges para defender la tesis de que éste es, en el fondo, un filósofo que "por modestia o prudencia se sirvió de la literatura" (Lemm 1991, p. 9). Según Lemm, el pensamiento de Borges no es irónico ni lúdico (o "surrealista", para citar una de las palabras anatematizadas por él) sino coherente y serio. Frente a los que consideran a Borges como un autor (post)moderno Lemm se erige en defensor de un Borges que rechaza el pensamiento y la literatura de su siglo. En sus análisis Borges casi se convierte en un creyente. Es significativo a este respecto que en un artículo sobre Jorge de Burgos, Lemm no interprete al personaje inventado por Umberto Eco en El nombre de la rosa como una ficcionalización basada en el Borges real sino como una fiel representación del mismo. (Lemm 1984)

De literator als filosoof fue contestado con fervor. Por un lado, algunos literatos negaron rotundamente que Borges fuera un filosófo, es decir un pensador sistemático (Pol 1977, pp. 158-168; Matsier 1998). Por el otro, algunos filósofos no negaron que se podría considerar a Borges como un filósofo (sin dejar de ser literato) pero ello sólo en el marco postestructuralista o postmoderno rechazado rabiosamente por Lemm (Heumakers 1992; Crego y Groot 1992). Heumakers recalca la ironía y el escepticismo de Borges, que parecen "un producto de la época post-metafísica que ya no puede creer en las antiguas certidumbres pero tampoco es capaz de renunciarlas" (Heumakers 1992) mientras que Crego y Groot concluyen que

es precisamente el exceso de seriedad de Lemm lo que le impide cumplir con la exigencia de tomar en serio la ironía de Borges. Su búsqueda de una concepción del mundo religiosa y metafísica no le permiten [sic] ver que la escritura de Borges constituye, en el fondo, el firme empeño de esquivar esa metafísica. En el pensamiento escolástico en el que Lemm se mueve no hay espacio para la literatura como expresión de la verdad. (Crego y Groot 1992, p. 155)

En su artículo "Borges: fantast of filosoof?" (Borges: ¿iluso o filósofo?) el hispanista y traductor Erik Coenen defiende la empresa de Lemm de interpretar a Borges como filósofo (aunque el procedimiento y el resultado de esta empresa no le parecen logrados del todo) frente a las críticas de Barber van de Pol y Nicolaas Matsier, cuya lectura de Borges le parece sintomática de la de los lectores 
holandeses. Coenen está convencido de que Borges no duda de que ciertas convicciones son verdad, como por ejemplo la de que el universo es "un cosmos, un conjunto ordenado" y la de que el universo, en esencia, no es espacial sino temporal. (1999, p. 14) Es curioso (y significativo) que Coenen no comente las críticas de Heumakers y de Crego y Groot, que asimismo toman en serio el ideario filosófico de Borges pero defienden una interpretación diametralmente opuesta a la del hispanista.

Otro debate surgió a raíz de "Una carta a alguien que nunca haya leído a Borges" escrita por el prestigioso autor Willem Jan Otten en $N R C /$ Handelsblad. Se trata de una curiosa reseña con motivo de la traducción holandesa de El hacedor (Otten 1988). Aunque es un gran admirador de Borges, Otten pone ciertos reparos al universo borgiano. Barber van de Pol salió en defensa de Borges alegando que no se le puede echar en cara a Borges la falta de una temática sexual en su obra, como hace Otten. "Es como reprochar a Kafka que en sus cuentos Praga figure mucho y Parimaribo nunca," advierte Van de Pol entretejiendo la indignación y la ironía (Pol 1997, p. 171). Borges no es "un solipsista árido" (ibídem) puesto que la temática sentimental y erótica no falta en su obra que, además, no sólo excita la razón sino también los sentidos. Van de Pol advierte, asimismo, que es errónea la afirmación de Otten de que Borges permaneció ajeno a las dos guerras mundiales (ibídem: 169).

Van de Pol es, sin duda alguna, la crítica más polifacética de la obra de Borges en Holanda. Además de profundizar en la cosmovisión idealista y las metáforas más conocidas de Borges - es decir, en el Borges 'irreal': la vida como sueño; la ilusión del yo; el gran afán y la defectuosa capacidad epistemológicos del hombre; el universo como biblioteca o libro; el laberinto; el espejo; el doble; el tigre - Van de Pol escribió ensayos sobre, entre otros temas, Borges y el tango y Borges y la cábala. Hay que añadir, sin embargo, que ella tampoco ha profundizado mucho en el contexto histórico y político del discurso borgiano. Llama la atención, asimismo, la insistencia con la que Van de Pol ha defendido la tesis de que la actitud de Borges es a-académica (o 'lúdica', si se quiere).

Las afinidades de Van de Pol empalman con las de los autores mencionados y citados arriba: Harry Mulisch, Cees Nooteboom, Doeschka Meijsing y sus compañeros de De Revisor, revista de la cual Van de Pol fue redactor en los años ochenta. No es de extrañar, pues, que en el título de la novela con la que en 1998 debutó como 
novelista refiere claramente a Borges: Er was wat met meneer en mevrouw Maker (Pasaba algo con el señor y la señora Hacedor, 1998).

Hace algunos años Van de Pol tradujo Historia universal de la infamia, Ficciones y El Aleph. Se trata de una versión completamente nueva de los primeros tres libros de cuentos de Borges, cuya primera traducción holandesa (de A. Sillevis) dejaba que desear, como ya señalaron algunos críticos a mediados de los años sesenta (ver más arriba). Las nuevas versiones de estos tres libros de cuentos forman el primer tomo de las Werken in vier delen (Obras en cuatro tomos) que aparecieron a finales de los años noventa y que, aparte de estas (y algunas pocas otras) nuevas traducciones, contienen reediciones de los libros traducidos y publicados en las décadas anteriores. La edición es preciosa pero es de lamentar que apenas se hayan incluido comentarios y notas. Es reveladora, a este respecto, la aguda diferencia con las obras completas en francés editadas en Pléiade (tomo 1: 1993; tomo 2: 1999).

Así, se perdió lo que podría haber sido una excelente oportunidad para ampliar el horizonte de los lectores holandeses de Borges. Para Holanda, empero, Borges sigue siendo casi exclusivamente el autor de la irrealidad, como muestran las extensas reseñas que aparecieron con motivo de las Werken in vier delen. Sólo Ilse Logie - no es nada casual que se trate de una crítica flamenca, muchas de cuyas reseñas para el diario belga De Morgen también aparecían en el diario holandés Trouw - ubica a Borges en su contexto nacional, que para los otros críticos apenas suele tener relevancia. Así, en Vrij Nederland Nicolaas Matsier se limita a rastrear la originalidad de Borges, que estribaría en su "obsesión" por los arquetipos (el hombre, el tiempo, el lugar), en su particular erudición y en su brillante ars combinatoria (Matsier 1998). En de Volkskrant Willem Kuipers afirma rotundamente que a Borges "no le importaba la realidad que se suele llamar sociedad." (Kuipers 1998) Y en NRC/Handelsblad Ger Groot sostiene lo siguiente: "Con sus incesantes referencias [...] a libros [...] y autores oscuros, Borges es, sin duda alguna, la encarnación por antonomasia de este mundo libresco de papel que se toma a sí mismo por todo el universo." (Groot 1998) Y sin embargo, añade Ger Groot, "a veces también el mismo Borges parece desear una realidad que ya no esté intercalada en un libro o una palabra sino que simplemente es lo que es." (Ibídem) Se trata, según Groot, de un deseo que ocupa un lugar central en la poesía de Borges: "Lo que en su prosa tenía que negar Borges, en su poesía se convierte en el 
objeto de su deseo: la realidad irreducible que las palabras necesitan para significar algo, y que éstas nunca podrían sustituir." (Ibídem)

\section{Conclusiones}

La recepción de la obra de Borges - incluidos los debates provocados por ella - ha sido protagonizada por autores, traductores y críticos periodísticos. Brilla por su ausencia la participación académica, pues. Tanto para los editores como los críticos y los autores holandeses, el marco referencial de la obra de Borges ha sido casi exclusivamente textual. Según varios de ellos han afirmado en más de una ocasión, incluso muchos de los textos a que Borges alude serían ficticios (una idea combatida con fervor en Coenen 1999), con lo cual la irrealidad del marco referencial borgiano sería elevada al cuadrado. La 'realidad' borgiana se desarrollaría, pues, fuera de una realidad concreta e histórica. Sería más bien un espacio lúdico en que teorías sobre la ontología del universo se encuentran y quedan 'desenmascaradas' como conjeturas sin base 'real' gracias al genio de Borges, para quien la realidad sería, a lo sumo, un deseo, como sugiere su poesía a juicio del crítico literario y filósofo Ger Groot. Como escribió Paz en su lúcida necrología (1986, p. 27) Borges fue un enamorado de las ideas en cuyo interior "pelearon el metafísico y el escéptico". En este marco hay que ubicar los notables debates sobre la(s) creencia(s) de Borges con motivo del poema "El Angel" y del estudio De literator als filosoof de Robert Lemm.

Se podría decir que se trata de una visión reductiva del rico y polifacético universo de Borges, que - recuérdese - no sólo agradeció el ajedrez, el hexámetro y Paul Verlaine (es decir, 'textos') sino también el jazmín, los tigres y la luna, es decir la realidad, como escribe en el poema autobiográfico "La fama" (de $\mathrm{La}$ cifra). Esta interpretación 'miope' de la obra borgiana no ha sido contestada ni completada por la crítica académica. Pero quizás sea más justo afirmar que se trata de una lectura tan reductiva como fructífera ya que si en Francia Borges dejó sus más profundas huellas en la filosofía ${ }^{11}$, en Holanda las dejó en la literatura. Es significativo a este respecto que en el centenario del nacimiento de Borges no se organizara ningún congreso pero sí se ubicara al autor argentino en el foco del interés del mayor festival literario de Holanda, De Wintertuin (El Jardín de Invierno). Las siete conferencias que dieron otros tantos autores ${ }^{12}$ sobre los temas que Borges había abordado en Siete noches son otra muestra de la 
viva presencia de Borges en la literatura holandesa, de la que sólo me ha sido posible trazar los contornos aquí. ${ }^{13}$

\section{Notas}

1. En 1996 apareció la traducción española, realizada por el propio autor: ¿Fuera de contexto? Referencialidad histórica y expresión de la realidad en Borges. Citaré de esta edición.

2. Se trata de tres cuentos de Ficciones ("Pierre Menard, autor del Quijote", "El jardín de senderos que se bifurcan", "El milagro secreto"), tres de El Aleph ("La escritura del dios", "Historia del guerrero y de la cautiva", "El hombre en el umbral") y uno de El informe de Brodie ("Guayaquil").

3. Fictions (Paris, 1953), Labyrinthe (München, 1959), Labyrinths (New York, 1962) y Ficciones (New York \& London, 1962).

4. Una acotación: por aquel entonces el inglés, el francés y el alemán formaban parte del programa obligatorio de todos los tipos de la enseñanza media holandesa, por lo cual las personas formadas solían ser capaces de leer textos escritos en cada uno de estos tres idiomas.

5. Compárese lo que sostiene Mario Vargas Llosa en su apasionada conferencia "Las ficciones de Borges". Según el autor peruano, se trata, por una parte, de "uno de los mundos más literarios que haya creado escritor alguno, porque en él los personajes, los mitos y las palabras fraguados por otros escritores a lo largo del tiempo comparecen de manera multitudinaria y continua, y de forma tan vívida que han usurpado en cierta forma a aquel contexto de toda obra literaria que suele ser el mundo objetivo." (Vargas Llosa 1990, p. 473) Sin embargo, por otra parte "(...) no es un mundo desasido de la vida y de la experiencia cotidiana, sin raíz social. Está tan asentado sobre los avatares de la existencia, ese fondo común de la especie, como todas las obras literarias que han perdurado." (Ibídem: 474)

6. Maatstaf juli 1958, pp. 327-336.

7. Unos años después, Bernlef tradujo "La otro muerte", basándose en la versión inglesa del cuento aparecida en 1968 en The New Yorker. La traducción se publicó en Barbarber, revista co-fundada por Bernlef (núm. 72, mei 1969, pp. 9, 11, 14).

8. De Mierenmoordenaar (Historias de cronopios y de famas, 1967), Brief aan een meisje in Parijs (una compilación de cuentos de Bestiario y Final del juego, 1969) y Het kwijlen van de duivel (una compilación de cuentos de Las armas secretas y Todos los fuegos el fuego, 1969).

9. Haagse Post 13-11-1982, p. 23.

10. Cuentos: De Zahir (1967); Zes raadsels voor Parodi (con Adolfo Bioy Casares, 1968); Wereldschandkroniek (1970); Kronieken van Bustos Domecq (con Adolfo Bioy Casares, 1971); Het boek van de denkbeeldige wezens (con Margarita Guerrero, 1976); Het boek van zand (1977); Het verslag van Brodie (1979); De roos van Paracelsus en Blauwe tijgers (1982); De maker (1988). Poesía: Lof der duisternis (1977); Gedichten (1980); Het geheimschrift (1984); De gezworenen (1986). Ensayos: De cultus van het boek (1981); Zeven avonden (1983); De geschiedenis van de eeuwigheid (1985). La selección confirma que el interés por la vertiente argentina de la obra de Borges es escaso.

11. Ver, por ejemplo, "Borges y Nouvelle Critique" (Revista Iberoamericana julioseptiembre 1972, pp. 367-390).

12. Stefan Hertmans ("La Divina Comedia"), Tsjêbbe Hettinga ("La ceguera"), Piet Meeuse ("La cábala"), Erik Menkveld ("El budismo"), Marcel Möring ("La pesadilla"), Barber van de Pol ("La poesía”) y Hafid Bouazza ("Las mil y una noches”). 
13. El importante diario cristiano Trouw (7-10-2000) publicó la versión holandesa de "Deutsches Requiem" (El Aleph) en el marco de un debate con motivo de la afirmación del historiador alemán Gunnar Heinsohn de que el motivo de Hitler para organizar el holocausto fue que el dictador alemán quería destruir la ética y la moral, que según éste serían de origen judío. ¿Se asoma una reivindicación del otro Borges?

\section{Bibliografía}

Balderston, Daniel. ¿Fuera de contexto? Referencialidad histórica y expresión de la realidad en Borges. Rosario: Beatriz Viterbo, 1996.

Bernlef, J. "Het labyrinth van de tijd - Braziliaanse roman [sic]." De Groene Amsterdammer 10-10-1964a.

Bernlef, J. “"Bezige Bij' ontving Argentijnse auteur. Schrijverscollege bij Borges.” Het Parool 17-10-1964b.

Bernlef, J. "Jorge Luis Borges 1899-1986." Vrij Nederland/Boekenbijlage 28-6-1986, $3-4$.

Borges, Jorge Luis. "Vertaallaboratorium El Angel." New Found Land 1 (1981): 36-50.

Broyles, Yolanda Julia. The German Response to Latin American Literature and the Reception of Jorge Luis Borges and Pablo Neruda. Heidelberg: Carl Winter, 1981.

Caballero Wangüemert, Maria. Borges y la crítica. El nacimiento de un clásico. Madrid: Editorial Complutense, 1999.

Coenen, Erik. "Borges: fantast of filosoof?" Hollands Maandblad 12 (1999): 11-15.

Crego, Charo y Ger Groot. "Artículo-reseña de R. Lemm, De literator als filosoof." Foro Hispánico 3 (1992): 147-155.

Diepstraten, Johan y Sjoerd Kuypers. "Doeschka Meijsing: De geschiedenis van een fascinatie (zo zou ik elk boek van me wel willen noemen)," en Het nieuwe proza. Interviews met jonge Nederlandse schrijvers. Amsterdam: Athenaeum-Polak en Van Gennep, 1978, pp. 161-187.

Fens, Kees. "Schrijven als concurrerend scheppen. Verhalen van Jorge Luis Borges." De Tijd 12-9-1964.

Fens, Kees. "Symbolen rijgen tot verhalen. Tweede bundel van Jorge Luis Borges." De Tijd 17-10-1967.

Geenen, K. "Wonderlijke wereld van Jorge Luis Borges." de Volkskrant 14-1-1965.

Groot, Ger. "Het ene woord dat alles zegt. Jorge Luis Borges als filosofisch verteller." NRC Handelsblad 20-11-1998. Una versión ampliada se publicó en Streven 66:10 (1999): 898-909 bajo el título de "De spiegel en het echte woord. Honderd jaar Jorge Luis Borges."

Heumakers, Arnold. "Filosoof tegen wil en dank." de Volkskrant 14-2-1992.

Kuipers, Willem. "De bibliotheek is onbegrensd en periodiek. Eerste deel verzamelde verhalen Jorge Luis Borges." de Volkskrant 17-4-1998.

Lehmann, L.Th. "Fantasie en verstand." Litterair Paspoort 9:78 (1954): 142-143.

Lehmann, L.Th. "Essays." Litterair Paspoort 13:116 (1958): 102-103.

Lehmann, L.Th. "Een ongelooflijke erudiet. De Aleph van Jorge Luis Borges." Vrij Nederland 28-11-1964.

Lemm, Robert. "Heeft Umberto Eco een anti-Borges boek willen schrijven?' Maatstaf 1 (1984): 6-12.

Lemm, Robert. De literator als filosoof. De innerlijke biografie van Jorge Luis Borges. Kampen: Kok Agora, 1991.

Logie, Ilse. "De literaire wanhoop boven de cultus van het ik." Trouw 13-3-1998. 
Matsier, Nicolaas. "Denkt Borges? Het eerste deel van J.L. Borges' Verzameld Werk." Vrij Nederland 9-5-1998.

Meeuse, Piet. "In gesprek met Harry Mulisch.” De Revisor 10:6 (1983): 40-49.

Meijsing, Doeschka. "Jorge Luis Borges: door de spijlen van de eeuwigheid," en Hoe verliefd is de toeschouwer? Leiden: Nijhoff, 1988, pp. 1-17.

Mulisch, Harry. De Verteller verteld. Amsterdam: De Bezige Bij, 1971.

Nooteboom, Cees. El desvio a Santiago (4th ed.). Madrid: Siruela, 1996.

Nuis, A. "Jorge Luis Borges nu in het Nederlands." Het Parool 17-10-1964.

Otten, Willem Jan. "Brief aan iemand die nog nooit Borges gelezen heeft." NRC Handelsblad 9-12-1988.

Paz, Octavio. "El arquero, la flecha y el blanco." Vuelta 117 (1986): 26-29.

Peeters, Carel. Houdbare illusies. Amsterdam: De Harmonie, 1984.

Steenmeijer, Maarten. De Spaanse en Spaans-Amerikaanse literatuur in Nederland 19461985. Muiderberg: Coutinho, 1989.

Steenmeijer, Maarten. Bibliografia de las traducciones de la literatura española e hispanoamericana al holandés 1946-1990. Tübingen: Niemeyer, 1991.

Steenmeijer, Maarten. "Moderne klassieken: Borges, Rulfo, Paz en Cortázar opnieuw uitgegeven." Filter. Tijdschrift voor vertalen \& vertaalwetenschap 7:4 (2000): 55-62.

van Deel, T. "Borges en de Nederlandse literatuur." Vrij Nederland/Boekenbijlage 28-61986, 7.

van Doorne, J. "Argentijnse raadsels." Trouw 16-12-1968.

van de Pol, Barber. Alles in de wind. Amsterdam: Querido, 1997.

van Praag, J.A. "Geschiedenis der Spaans-Amerikaanse letterkunde." De Gids 8/9 (1956): 109-126.

Vargas Llosa, Mario. "Las ficciones de Borges," en Contra viento y marea, III. Barcelona: Seix Barral, 1990. pp. 463-476.

Zoon, Cees. "Borges groot Europees schrijver." De Volkskrant 8-10-1977. 